\title{
Laparoscopic Repair of Bilateral Inguinal Hernia in Female - A Case Report
}

\author{
Samiron Kumar Mondal ${ }^{1}$, Sharmistha Roy ${ }^{2}$

\begin{abstract}
:
Inguinal hernia is relatively uncommon in female, as compared to in males. The ratio of male to female is $6: 1^{1}$. The reason behind that is favorable stronger inguinal anatomy in females. This is a case of 59 years old lady presenting with pain in groin diagnosed as case of bilateral indirect inguinal hernia and was treated successfully by laparoscopic transabdominal pre-peritoneal (TAPP) hernioplasty.
\end{abstract}

Key Words: female inguinal hernia, Laparoscopic hernioplasty.

\section{Introduction:}

The incidence of inguinal hernia in female is $1.9 \%{ }^{1}$, but it is much more difficult to diagnose in female than in male. It is typical for women to have a non-palpable or occult inguinal hernia, paying several visits to their physicians and gynecologists complaining of chronic pelvic pain and yet remain undiagnosed.

\section{Case Report:}

Mrs A, a 59 year old lady presented to us with pain in the lower abdomen radiating to both thighs. On examination there was a bulge in both inguinal regions that disappear on lying flat and reappears on standing. Cough impulse test was positive. Ultrasonogram of the whole abdomen revealed no abnormality. She was diagnosed as bilateral inguinal hernia (Fig 1).

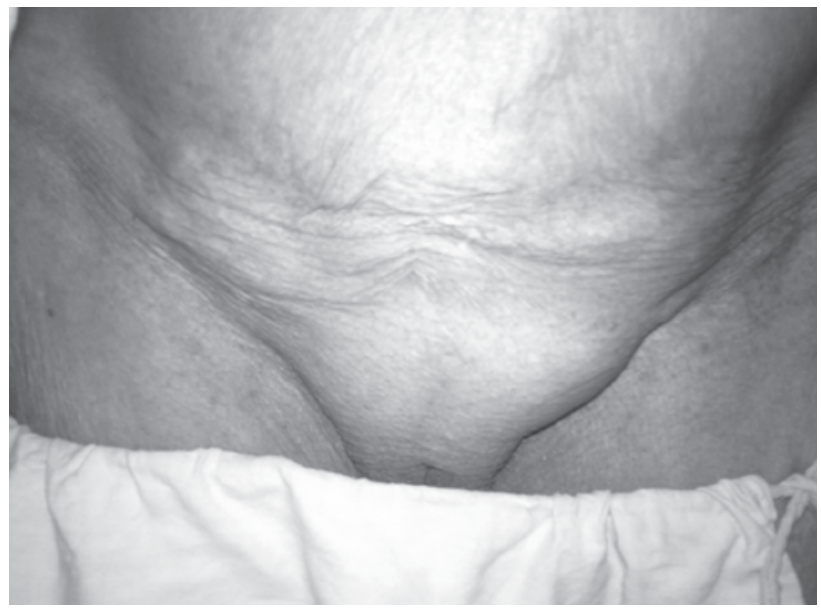

Figure 1: Ill defined bulge in groin, more prominent on the left

1 Dr Samiron Kumar Mondal, FCPS (Surgery), Associate Professor, BIRDEM General Hospital \& IMC

2 Dr Sharmistha Roy, FCPS (Surgery), Assistant Professor, BIRDEM General Hospital \& IMC

\section{Corresponding Author:}

Samiron Kumar Mondal

Associate Professor of Surgery

BIRDEM General Hospital \& Ibrahim Medical College

Dhaka 1000, Bangladesh

E-mail: drshamiron@yahoo.com
With all preoperative preparation, scope was introduced through umbilical port. Bilateral indirect inguinal hernia was found (Fig 2). Preperitoneal space was created by scissors and favoured with $\mathrm{CO}_{2}$ gas. Reduction of both sided hernia sac \& $15 \times 15 \mathrm{~cm}$ prolene mesh placed on both side and fixed with taker (autosuture). Finally peritoneal window was closed on both side.

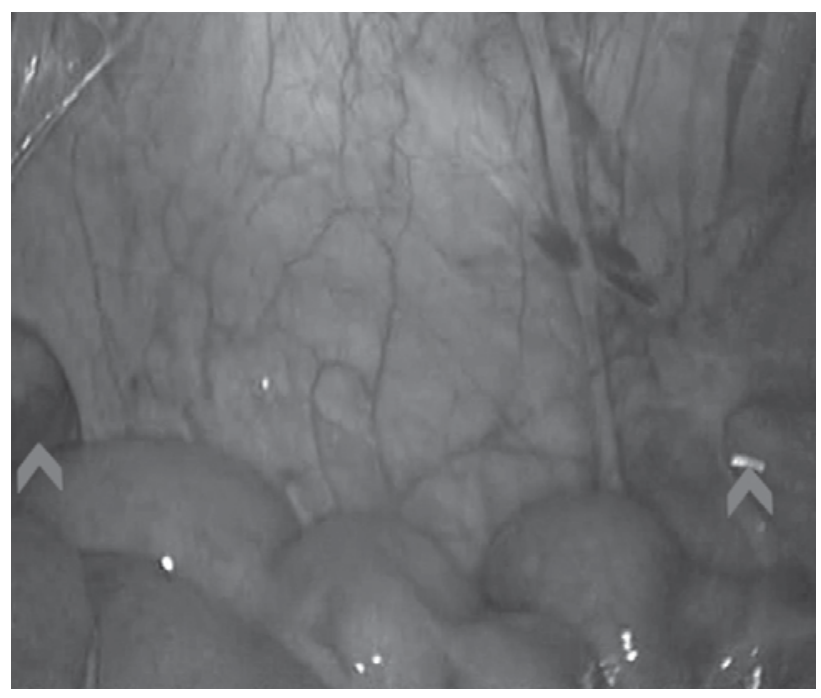

Figure 2: Laparoscopic view of hernia defects

Her post operative period was uneventful, and she was discharged on the $2^{\text {nd }}$ post operative day.

\section{Discussion:}

Inguinal hernia is one of the commonest of all hernias in male. This is also true for women in comparison to femoral hernia. For instance, in the Netherlands in 1994, there were approximately 3,500 operations for inguinal hernia in females out of a total of 33,000 operations ${ }^{2}$. Studies show 1 out of every 5 male, and 1 out of every 50 female will develop inguinal hernia in their life time ${ }^{3}$. The incidence is less in women than in men. Several studies were done to find out the predisposing factors; previous surgery, obesity, pregnancy, physical stress and smoking were found to be the leading cause in female acquired hernia ${ }^{2}$. Congenital hernia can also occur in female as in males due to failure of closure of the processus vaginalis. 
Diagnosis of inguinal hernia in the female is not as straight forward as in the male. Infact, at times this can be very challenging specially in very obese and elderly ladies with lax abdominal musculature in general and lax skin, as in our case. Most patients with acquired inguinal hernia have chronic pelvic pain as a symptom, some may have well localized pain in the affected inguinal region ${ }^{4}$. USG is an effective tool to diagnose larger complete hernias or often, irreducible ones. The surest and most effective way to diagnose female inguinal hernia is by laparoscopy ${ }^{5,6}$.

In our case patient had chronic pelvic pain, and pain in both groin. On clinical examination left sided hernia was more prominent but on laparoscopy hernia defect was found on both side, as reported in other studies. The study included 264 patients referred to a chronic pelvic pain clinic, who underwent 386 laparoscopic surgical repairs of hernial defects. $^{4}$

\section{Conclusion:}

Female patients suffering from chronic pelvic pain does not often present to a surgeon initially. So all medical practitioners, gynecologists, physicians, physiotherapists and pain specialists should also keep the possibility in their mind that pain may be due to a hernia. All patients should be examined in standing and supine position. As laparoscopy is the most effective tool to locate occult non palpable hernias, it is recommended to do a diagnostic laparoscopy in patients having hernia on one side, and thus it is convenient and rational to do a laparoscopic hernioplasty in the same go if expertise is available.

\section{References:}

1. Read RC, White JJ. Inguinal herniation. Am J Surg 1978; 136: 651-7.

2. Liem MSL, Graaf YVD, Zwart RC et al. Risk factor of inguinal hernia in women: A case control study. Am J of Epidemiology 1997; 146(9) : 721-6.

3. Chawla S. Inguinal Hernia in female. MJAFI 2001; 57: 306-8.

4. Perry CP, Villegus JD. Hernias as a cause of chronic pelvic pain in women. JSLS 2006; 10(2): 212-5.

5. Spangen L, Andersson R, Ohlsson L. Non-palpable inguinal hernia in the female. Am Surgeon 1998; 9: 574- 7.

6. Kavic MS. Chronic pelvic pain, hernias and the general surgeon. J Laparoendosc Surg 1999; 3: 89-90. 